Article

\title{
Sustainability and Resource Equilibrium Evaluation of a Tourism Traffic Network Based on a Tourism Traffic Matching Curve
}

\author{
Huiying Wen, Yuchen Zeng * and Zuogan Tang \\ School of Transport and Civil Engineering, South China University of Technology, Guangzhou 510006, China; \\ hywen@scut.edu.cn (H.W.); 201621007274@mail.scut.edu.cn (Z.T.) \\ * Correspondence: 201720107356@mail.scut.edu.cn
}

Received: 2 September 2019; Accepted: 15 October 2019; Published: 17 October 2019

\begin{abstract}
The accompanying increased traffic due to the rapid development of tourism at present calls for the better sustainability and equilibrium of tourism and traffic resources in the future. In recent decades, considerable attention has been paid to highway network planning, while studies focusing on sustainable tourism traffic networks, especially evaluation methods of limited tourism and traffic resources, have proven less successful. Through conceptual transfer, we proposed the tourism traffic matching curve, which not only simplifies the method of sustainability and equilibrium evaluation, but also ensures that the results are more direct and effective. In the upper layer, we analyzed the main factors of tourism traffic network development, which contributed to a comprehensive benefit-oriented multi-objective model of tourism traffic network in MATLAB. In this model, the long-neglected tourism economy radiation effect was considered, and a genetic algorithm was introduced in the solution. In the lower layer, the characteristics of the tourism traffic matching curve and the two crucial equilibrium indexes, the Tourism Traffic Uniformity Coefficient (TLCU) and Curvature Coefficient (TLCC), were provided. With instances from Guangdong Province, the proposed system was proven to be more efficient and concise than other systems, which identified the need for future research on establishing effective criteria and a theoretical analysis method for dynamic adjustment.
\end{abstract}

Keywords: resource sustainability; tourism traffic matching curve; network equilibrium; green benefits; genetic algorithm; MATLAB

\section{Introduction}

Today, tourism has become an important fiscal revenue source for both the government and local residents. As the carrier and engine of tourism development, tourism traffic has experienced a steady growth in recent years [1]. Moreover, the growth of both the regional mobility of tourists and tourist spot co-operation also contributes to the accompanying increase in traffic requirements [2]. To improve the sustainability and source combination of transportation and tourism, a new idea for future planning has been reported as being creative, coordinating, green, open, and sharing [3-6]. Only in this way can the optimization and evaluation system help to guarantee a high efficiency, safety and availability of tourism road networks. In the meanwhile, policy makers can also evaluate the sustainability of their policies in planning from different aspects.

The literature related to our research can be classified into two branches: (1) traditional highway network planning, and (2) tourism traffic planning.

\subsection{Traditional Planning of the Highway Network}

Research on the influencing factors of network construction in Western and Eastern countries has covered economic, geographic, and traffic conditions. Specifically, a study in the former Soviet Union 
substantiated the relationship between the road network scale and the level of local development, where multiple regression and correlation analysis methods were used. In Europe, researchers considered national territorial areas and per-capita gross national products [7]. In a later study in Japan, the territory coefficient method was proposed to prove that regarding the highway scale, there was a positive correlation with the traffic demand and a negative correlation with both the construction and maintenance costs [8]. In addition, the regional road network layout and the basic costs have attracted extensive interest in factor selection and sensitivity analysis of road network scale planning and optimization. The basic costs here included transportation, carbon emissions, and travel time based on reliability [9].

Furthermore, in road network layout optimization, empirical studies aimed to optimize modelling methods. A previous study successfully solved typical multistage dynamic network problems, where random arc capacities were employed in the variable resource allocation model. The tree structure of the large-scale problem allowed the subproblem calculation to be conducted more efficiently and accurately at each stage [10]. In a recent modelling study, the environmental influence turned out to be another important factor. For example, the transport efficiency improvement and carbon emission reduction characteristics of the data envelopment analysis (DEA) model have emerged as an interesting candidate in the objective optimization model [11]. In the network structure, problems such as network hierarchy classification also contribute to the introduction of the complex network theory and dual topology methods. Moreover, a weighted adjacency matrix based on the gravity model and variation coefficient method was used to ensure a suitable goodness-of-fit of the highway grade distribution [12].

To date, a considerable amount of research has been conducted to allow planning models to adapt to different conditions and to make more accurate results available. For example, Zhao et al. [13] optimized the capacity calculation through simulation with a computational urban-specific evolution model. This model was proven to function well in both one-centre and two-centre road networks. More importantly, the approach helped to determine the construction demand and the level of planning road. In the study of Wang et al. [14], the crucial role of the augmented improved Lagrange function was revealed by more than the calculation of the section road environmental capacity. In addition, the constraints of two influence factors in this function, i.e., the road capacity and traffic pollution, make it possible to control the road network capacity and pollution under different conditions. In another case, a new framework was proposed to quantify the network sensitivities explicitly in the coexisting network, consisting of a transit system and bike-sharing system. By solving the issue as a departure-time-elastic multicommodity flow problem, Chow et al. [15] proposed the potential dependency between these systems and verified the optimal discount values of bundled fares.

However, normal traffic network planning is facing challenges owing to the very large computation amount, which requires exerting much effort. The back-propagation (BP) neural network applied in multi-objective programming (BPNN-MOP) was adopted by Shi et al. [16] to obtain the optimal solution for the regional highway network scale. Based on the BP neural network and Markov chains, the multi-objective programming model could be used to describe the macro-and micro-fluctuation laws of highway network scale evolution. In the traditional polynomial algorithm, Ma et al. [17] introduced an improved genetic algorithm in the layout of rural highway networks. This method replaced the conventional crossover and mutation operations with single-transposition and ortho-position exchange operations, respectively, to reduce the length of the chromosome. Under the genetic algorithm, the accuracy and reliability of the results were greatly improved.

\subsection{Tourism Traffic Planning}

The rapid development of tourism resulted in tourist spots becoming wide-spread traffic sources in not only megacities but also in rural areas. The accompanying increased traffic calls for a better transportation system. Since highway networks shoulder critical and considerable responsibilities of carrying the door-to-door traffic volume, it is necessary to achieve a balance between tourism and traffic resources so that these resources can be utilized with high efficiency and safety levels. 
Regarding tourism traffic planning, researchers have studied different aspects. The first priority is undoubtedly the influence factors. For instance, with the use of time-space geography, Recker et al. [18] analyzed tourist accessibility related to the promoting effects of real-world ride-sharing and trip-chaining behaviours. In that study, spatiotemporal constraints and household interaction effects were utilized to measure their mutual influences on the established environment. Among all these factors, it is no surprise that the traffic source plays an important role. Focusing on the population components of traffic flow, Li et al. [19] employed recognition technology to assist the traffic planning of city-endorsed tourist attractions. The management of the tourism traffic demand for island attractions also received much attention in the same way [20]. In addition to traffic flow coordination, subsidiary measures should be implemented as well. For example, Ho et al. [21] analyzed the ticket prices of tourism traffic in established tourist attractions and built a planning model to describe the relationship between these aspects. It was reported that adjusting the ticket price in traffic flow control could partially alleviate traffic pressure. Ding et al. [22] determined the relationship between the tourism economy and highway distribution before the vector autoregressive (VAR) model was introduced. Furthermore, it was reported that the research in developed countries focused more on the service level of highways, while the research in developing countries tended to place more emphasis on the socioeconomic benefit.

In the construction of a tourism traffic network, there are many more limitations to the research. For example, Mirabueno et al. [23] built a collaborative optimization model of tourism project development and expressway networks. However, this model neglected the environmental and geographical influences in its practical construction. Aaheim et al. [24,25] exploited the coupling mechanism between self-driving tours and highway networks. Unfortunately, only the tourist, traffic, and destination types were considered, while the induced traffic of tourist attractions was not studied. A later study conducted by Marek et al. [26] provided a tourism highway yield calculation model based on resource availability, but the model has a disadvantage in that the network scale limit in terms of the capacity and intensity, which is believed to be subject to local policy and physical conditions, is neglected. Furthermore, previous tourism-related traffic planning studies have focused more on sustainable resources, while optimizing the equilibrium evaluation method of the tourism traffic network has not attracted enough interest. Based on user data, Abdelghany et al. [27-29] stressed the importance of efficiency and assignment to the evaluation of various functional and economic policies before proposing dynamic user equilibrium (DUE) models, which proved to function well in the evaluation of traffic control and demand management. The variational inequality (VI) problem proposed by Smith et al. [30-32] was then solved in another way by Lu et al. [33,34]. With the use of the gap function, the VI was reformulated, but the real behaviours were not properly represented. Considering the impact of the sociodemographic background, traveller heterogeneity has been considered in recent years $[35,36]$. Focusing on the activity-trip chain demand, a general simulation-based dynamic network equilibrium algorithm for assignment was subsequently developed [37]. Note that most studies mentioned above concentrate on model and algorithm optimization instead of evaluation of the current network.

Overall, sustainability and resource equilibrium evaluation of the tourism traffic network deserves more attention, because it paves the way for reaching the goal of green development in network planning. More importantly, the approach unlocks the critical bottleneck of how to meet the increasing tourism traffic requirements, and provides a theoretical method to simplify the evaluation and make the impact of the results more effective and direct.

The remainder of this paper is organized as follows. In Section 2, we formally define the tourism traffic curve and explain the flow of the proposed double-layered system. Section 3 examines the modelling issues and corresponding parameter determinations in the upper layer. Then, we describe the drawing method and the characteristics of the tourism traffic curve of the lower layer in Section 4. In the same section, two equilibrium evaluation indicators are given. Our case study is introduced in Section 5, where the optimization and evaluation system in this paper is demonstrated to make the 
evaluation more efficient as well as convenient in its expression. Moreover, a comparison with the current distribution of the tourism road network in a given area and the optimal parameters of the genetic algorithm in the model solution are presented. Section 6 provides final remarks, including highlights, potential applications of this system, and follow-up research.

\section{Theory}

\subsection{Assumption of Traffic Tourism Matching Problem}

On the one hand, resources matching evaluation of tourism and traffic are central to attaining a high efficiency of vehicle operation and regional balance of development in a tourism traffic network. However, since previous studies have placed very limited emphasis on tourism traffic, there is still a great need for an effective evaluation system. On the other hand, because conventional models generally employed multi-objective optimization to make the network scale of different classes available, the planning schemes were provided simply at the macro-level. Hence, the guidance value on resource levelling remains limited. To issue advice on utilizing tourism and traffic resources in a more efficient and proper way, we propose an equilibrium evaluation method in tourism traffic via conceptual transfer.

In civil engineering, it is widely recognized that the soil skeleton is composed of solid particles. Their size and content could change the physical properties of the skeleton structure. Thus, the grain size distribution is believed to be of great importance to the subgrade stability. In practical projects, the grain size composition is generally adjusted to eliminate the step phenomenon in grading. In this way, a good match would become available, which makes it possible to reach the required bearing capacity under safe conditions. To provide an accurate evaluation of the grain size distribution and size grading, a grain size grading curve is suggested. Based on the size screening results, the abscissa of the curve represents the size of the solid particles, and the ordinate shows the cumulative percentage of the corresponding mass. Through these data, the coefficients of both uniformity and curvature could be calculated to evaluate the grain size distribution.

Similarly, a tourism traffic network consists of tourism nodes with different degrees of importance. Here, the importance degree of the node acts as the particle size in the soil skeleton. In other words, the nature of both the skeleton and network structures would be analogously influenced by the composition. Therefore, when the importance degree of a node is high and the highway scale is relatively small, the network may fail to meet the traffic requirement in terms of the capacity and service level. Likewise, the accessibility of the network would also be affected under these conditions. On the other hand, when the importance degree of a node is low and the highway scale is overly large, the highway network around the node is not fully utilized. This situation would not only be a waste of social resources, but would also lead to a potential increase in the unnecessary maintenance costs of the roads. Therefore, reasonable proportioning is undoubtedly the mutual goal of both civil and traffic engineering applications.

By introducing the grain size distribution from the perspective of civil engineering, a relationship is built between traffic and civil engineering. The process is shown in detail in Figure 1. 


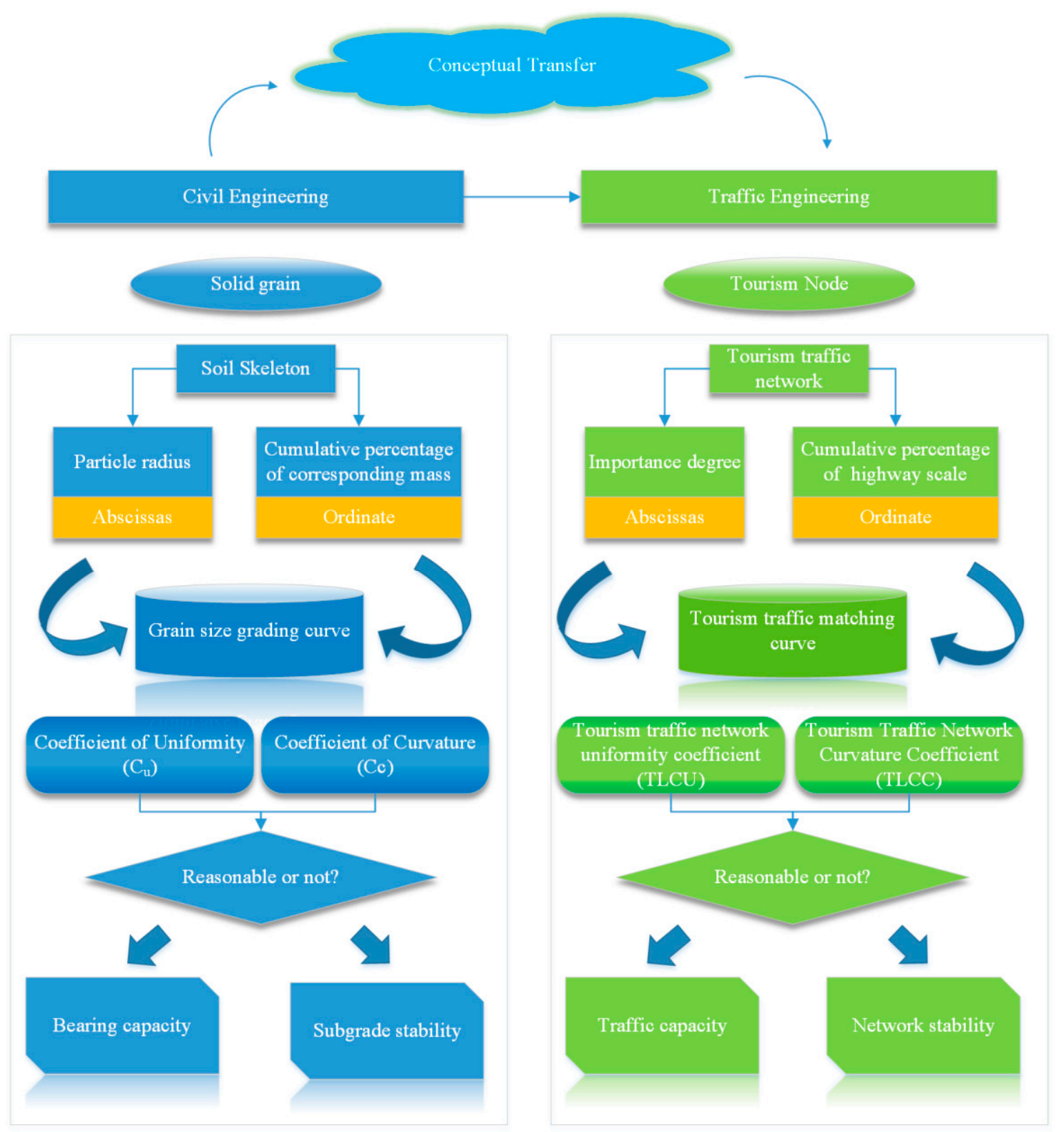

Figure 1. Conceptual transfer of the tourism traffic matching curve.

As shown in Figure 1, we introduce tourism traffic matching curves and corresponding indicators, including the Tourism Traffic Network Uniformity Coefficient (TLCU) and Tourism Traffic Network Curvature Coefficient (TLCC). These achievements would not only provide an effective and direct criterion for the equilibrium of the tourism traffic network as a whole, but would also provide a tourism and traffic resource planning approach for any specific node in the network. Moreover, the judging standards and the result expressions could be optimized through the proposal method.

\subsection{Evaluation and Optimization Method}

In this paper, a double-layered coupling system is constructed. The upper layer of the structure contains the tourism traffic multi-objective optimization model, which could potentially be solved by the genetic algorithm. The lower layer puts the tourism traffic matching curve into practice and provides corresponding indicators to evaluate and optimize the equilibrium of the tourism traffic network. The flow path is shown in Figure 2. 


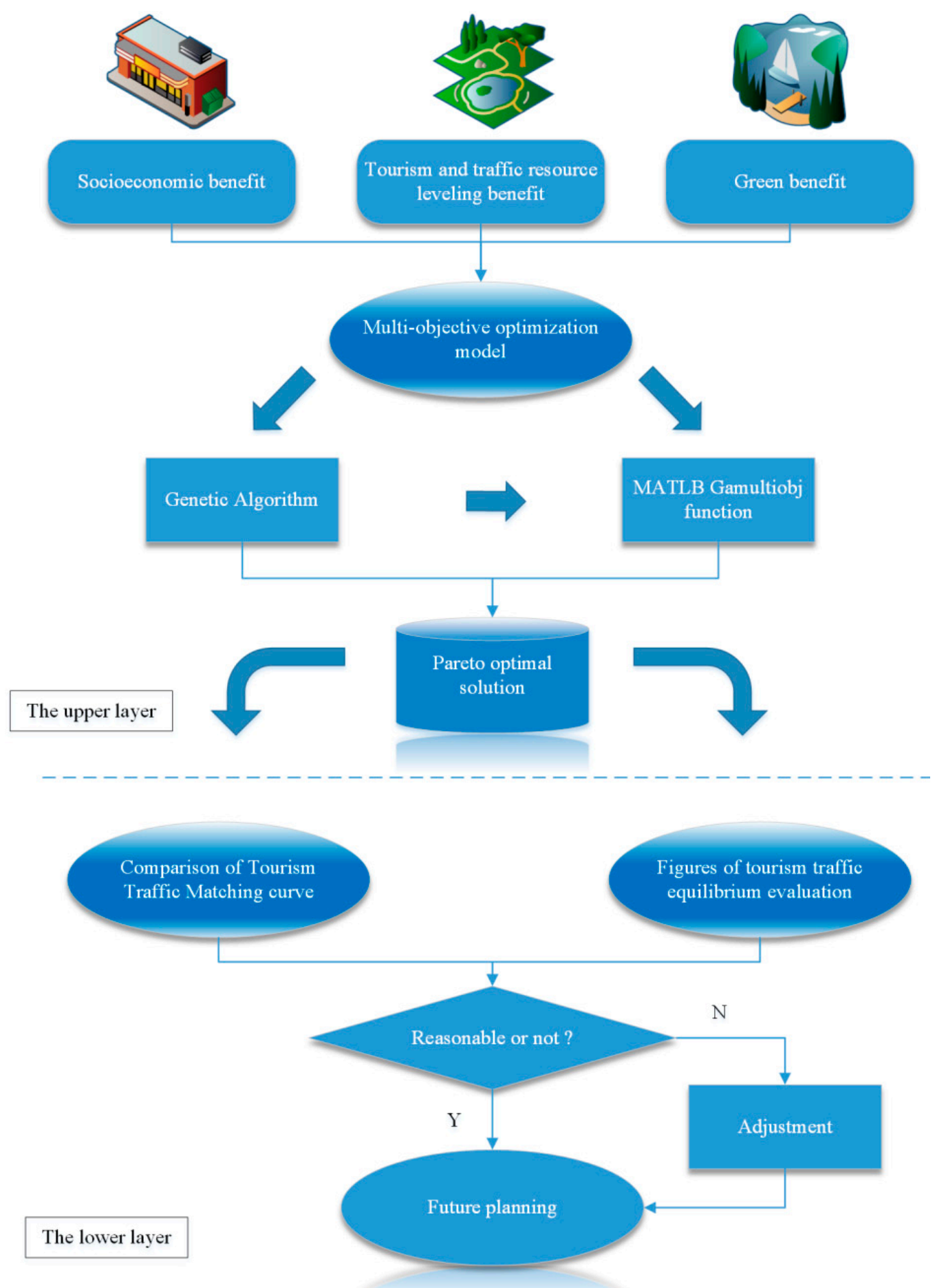

Figure 2. Flow chart of the double-layered coupling system of optimization and evaluation.

The explanation of the flow path is given as follows:

Step 1: Build the multi-objective optimization model aimed at socioeconomic, tourism and traffic resource levelling and green benefits.

Step 2: Obtain basic regional data from government institutes or authorities to determine the parameters in the proposed model and establish the upper layer of the system.

Step 3: Solve the model with the genetic algorithm or the Gamultiobj function in MATLAB, which is suggested in this paper considering the computational cost. 
Step 4: Calculate reasonable indicator values of the network equilibrium in the lower layer based on the results of the upper layer, including the upper and lower boundaries.

Step 5: Plot the tourism traffic matching curve of the current network.

Step 6: Calculate values of the two indicators of the equilibrium of the current network and compare these values with the evaluation standards.

Step 7: Evaluate the equilibrium of the overall network and specific nodes.

Step 8: Determine the future planning and adjustment schemes.

\section{The Upper Layer of the System}

Optimization of the tourism traffic network should not only meet the basic requirements of traditional road network planning in terms of traffic growth, construction funding, and service levels, but should also focus on tourism resources and the ecological environment. Therefore, in this paper, the main influence factors of the tourism traffic network are classified into three aspects: socioeconomic benefits, resource levelling, and green benefits. The results would be evaluated through the trip distribution, and any index out of range would require a new iteration until all conditions are satisfied.

In general, the upper layer of the system in this article assumes that: (1) All the basic data of the highway network and the tourism nodes are given, including the number of lanes, tourist arrivals and anticipated project investment of each tourism node in the given network; and (2) The optimization allows the vehicles in the tourism traffic network to run under ideal conditions, that is, the road capacity and vehicle speed are assumed to reach the free condition after the optimization.

\subsection{Model Variables}

\subsubsection{Socioeconomic Benefits}

The socioeconomic benefits mainly consist of the optimization cost of the tourism traffic network and the time cost saved for road users. Due to the influence degree and time delay, indirect benefits such as the fuel cost and passenger comfort can be considered in future research instead of in this study. In this benefit-oriented model of highway network optimization, the socioeconomic benefits constitute a positive index [38]. We utilize the following equation:

$$
E_{s}=E_{1}-E_{2}
$$

where $E_{s}, E_{1}$, and $E_{2}$ represent the socioeconomic benefit, the time cost saved for road users, and the construction cost in network optimization respectively.

Specifically, traveling time cost of per-unit could be calculated through gross domestic product as discussed elsewhere $[39,40]$. In addition, based on the Bureau of Public Roads (BPR) impedance function, users' time that is saved in the optimization equals to the difference value between the present and the optimal travel time. Consequently, the time cost that is saved for road users could be calculated as:

$$
E_{1}=C_{t} \sum_{a \in A} \delta_{a} q_{a} t_{a 0} \alpha\left(\frac{q_{a}}{C_{a}}\right)^{\beta}
$$

where $C_{t}$ is the time cost saved in the network optimization, depending on the per-capita gross national product of the given area in the planning year. $A, a$ and $\delta_{a}$ are sets of paths, being any one path in particular, and the path decision variable in the network, respectively. Paths here include newly-built and rebuilt ones. Note that we set the path decision variables $\delta_{a}=0$ or 1 , and 1 if this path is selected in the route determination. $q_{a}, t_{a 0}$ and $C_{a}$ are the traffic flow of passenger car units, the free travel time and the actual capacity in path $a$. Traffic flow here includes the induced traffic of tourism. $\alpha$ and $\beta$ are both coefficients of BPR impedance function, which are set as 0.15 and 4.00 respectively in general. 
On the basis of local authoritative standards and guidelines, the construction cost of the network optimization could be evaluated as the following formula [39]:

$$
E_{2}=\sum_{a \in A} c_{a} L_{a}
$$

where $c_{a}$ is the unit cost highway in the given network. Highway here includes newly-built and rebuilt ones. $L_{a}$ is the length decision variable of a certain path in the same area.

\subsubsection{Leveling Benefits of Tourism and Traffic Resource}

The levelling benefits of tourism and traffic resources comprise both the investment and income of tourism projects. Similar to the socioeconomic benefits, the tourism and traffic resource levelling benefits also function as a positive index in the objective optimization model of the highway network in terms of previous study results [41], of which we utilize the following equation:

$$
E_{t}=E_{3}-E_{4}
$$

where $E_{t}, E_{3}$, and $E_{4}$ represent the leveling benefit of the tourism and traffic resource, the tourism project income and the investment of certain nodes respectively.

Specifically, the radiation effect of the tourism resource unit or cluster was proven to promote traffic volume growth and encourage tourism economy development in the surrounding tourism nodes [42,43]. Furthermore, there is no doubt that different tourism nodes have a different status in resource allocations combined with the construction demand. Then, these differences would contribute to heterogeneity in the network optimization. By introducing the importance degree of the tourism node, the radiation effect of the tourism economy could be better described. Thus, we would assign proper weights to the tourism nodes in accordance with their different importance degrees [44]. Basically, the tourism project income of the nodes in the tourism traffic network could be calculated as follows:

$$
E_{3}=\sum_{\mathrm{p} \in \mathrm{P}} I_{p} e_{p}\left(\delta_{p} Q_{p}+q_{p}\right)
$$

where $P, p$, and $\delta_{p}$ are the tourism projects of nodes assemble in given area, the tourism projects in any one node and the node decision variable in the given network, respectively. The tourism projects here include newly-built and rebuilt projects. We set the node decision variable at $\delta_{p}=0$ or 1 , and 1 if this node is selected in the development planning determination. $I_{p}$ and $e_{p}$ are the importance degree and the tourism project income of the unit vehicles, which could be evaluated by per-capita expenditure and the loading rate of vehicles of the tourism project in the certain node $p$ in question. Data normally comes from field surveys and data collection by local government. $Q_{p}$ and $q_{p}$ are the induced traffic flow and the basic traffic volume of passenger car units in the certain tourism node $p$ separately. Note that the generation of the traffic flow here incorporated all the users, including common users and tourists.

The tourism project investment includes the construction cost of both newly-built and rebuilt tourism project [42]. Its formula could be utilized as follows:

$$
E_{4}=\sum_{\mathrm{p} \in \mathrm{P}} C_{p} \delta_{p}
$$

where $C_{p}$ is the tourism project investment of node $p$ in the given tourism traffic network.

\subsubsection{Green Benefits}

Carbon dioxide is recognized as the key pollutant of vehicle operation in the road network, which is set as a fundamental index of environmental influence [45]. Furthermore, the carbon emission model 
of motor vehicles is widely used in recent research, and so we introduced it into the tourism traffic network $[46,47]$. With regards to the gross carbon emission per-unit distance in the planning area of the road network, we utilize the following formula:

$$
E_{e}=\sum_{a \in A} \sum_{\mathrm{k}=1}^{6} q_{a k} C_{a k} L_{a}
$$

where $E_{e}$ is the quantitative index of environmental influence, performing as a negative index in the objective function. $q_{a k}$ is the vehicle number of type $k$ on the path $a . C_{a k}$ is the carbon emission per-unit distance in the planning area of the road network. To be specific, carbon emission of different vehicle types at different speeds could be found in the previous study [46].

\subsection{Model Optimization and Constraints}

\subsubsection{Constraints}

Considering the actual conditions of the tourism traffic network, the objective model of highway network optimization should be subject to the following constraints:

1. The scale of a given highway network meets the network demands for the planning year,

2. The capacity of a given highway network meets the capacity demands for the planning year,

3. The service level of a given highway network meets the service level demands for the planning year,

4. The traffic volume of the paths equals that of the nodes in the given highway network,

5. The sum of the weights of all the segments equals 1 in the proposed model, and

6. All the parameters are nonnegative.

\subsubsection{Function Standardizing}

In order to eliminate the effect of the data range, objective functions in the proposed model should be standardized in advance, before being given different priorities. Since the objective function is expected to reach the maximum of the comprehensive benefits, we could get the ultimate objective function through direction uniformity. The formula is shown as follows:

$$
\begin{gathered}
\min Z=-\tau_{1} E_{s}^{*}-\tau_{2} E_{t}^{*}+\tau_{3} E C O^{*} \\
E_{s}^{*}=E_{s} / k_{s} \\
E_{t}^{*}=E_{t} / k_{t} \\
E_{e}^{*}=E_{e} / k_{e} \\
\operatorname{s.t}\left\{\begin{array}{c}
\sum_{a \in A} L_{a}=L_{N} \\
\sum_{a \in A} C_{a} \delta_{a} \geq \sum_{p \in \mathrm{P}} q_{p} L_{a} / \mu \\
\lambda_{\min } \leq \frac{Q_{n}}{C_{a} \delta_{a}} \leq \lambda_{\max } \\
\sum_{a \in A} q_{a k} \delta_{p}=Q_{p}+q_{a} \\
\tau_{1}+\tau_{2}+\tau_{3}=1 \\
L, C, Q, q, \mu, \lambda, \tau \geq 0
\end{array}\right.
\end{gathered}
$$

where $E_{s}^{*}$, $E_{t}^{*}$, and $E_{e}^{*}$ are standardized socioeconomic benefits, leveling benefits of tourism and traffic resources, and green benefits. $k_{s}, k_{t}$ and $k_{e}$ are their weight respectively, which should be determined by the field survey and local plan made by authoritative institute. $\tau_{1}, \tau_{2}$, and $\tau_{3}$ are the coefficient of them, which should render the value of three segments of the objective function to maintain a level 
at the range from 0 to $1 . L_{N}, \mu, \lambda_{\max }$, and $\lambda_{\min }$ are the scale, the traffic volume, the saturation degree, and the design service level boundary of the given highway network in the planning year. Note that all these parameters should refer to the field survey or local plan made by authoritative institutes.

\subsubsection{Test Standards}

To verify the rationality of the optimized network, a proper traffic assignment model is required to evaluate the performance of the planning network. The mode of the trip assignment in conventional network optimization could be classified into two types: dynamic user equilibrium (DUE) and dynamic systemic optimal (DSO). The modes respectively focus on the shortest path or travel time and the travel cost in the whole network. Considering the sustainability and green effect as well as the plentiful financial support for the current network, the DUE trip distribution mode is adopted in this paper. This method was proposed and successfully applied to a series of network planning schemes [47]. Following the algorithm of Frank-Wolfe [48], the trip distribution is obtained and would be incorporated in the objective optimization model in Section 3.2.2. In this step, traffic parameters, including traffic flow volume and service level, would be evaluated against any of the constraints in Section 3.2.1. Otherwise, the paths that are out of range would be penalized to limit the use of these paths so that the constraints could be satisfied again. The process would not stop until the maximum generation was reached or the value of the error relative to the initial distribution was acceptable. The DUE objective function can be presented as the following equation:

$$
\min Z_{0}=\sum_{a \in A} \int_{0}^{q_{a}} t_{a}\left(C_{t}\right) d\left(C_{t}\right)
$$

\section{The Lower Layer of the System}

As a prerequisite of the lower layer of the system, the tourism traffic matching curve is defined. A demonstration of its fundamental characteristics will also be given in the first section of this chapter. Then, with the assistance of two crucial indicators, the judgement criterion of the network equilibrium evaluation will be established in the second part of section.

\subsection{Tourism Traffic Matching Curve}

The tourism traffic matching curve shows the network allocation in the tourism nodes with different importance degrees. In the line chart, the abscissa is the importance degree of the tourism node, and the vertical axis is the cumulative percentage of the network scale. The slope change of the curve allows the equilibrium of allocation of the network to be evaluated. A low degree of change indicates a poor match, and that the highway scale varies slightly with increasing importance degree and corresponding nodes. A notable slope change can indicate that the allocation of the highway scale fits the importance degree of the node well, which is a necessary condition of the desired match.

Now, we provide proof of the basic characteristics of the tourism traffic matching curve. The first priority is the calculation of the importance degree of each node, where necessary data on socioeconomic, transport, and environmental factors were all considered, and the typical factors were selected for the evaluation. Normally, tourism traffic network nodes are subject to the influences of traffic factors, such as highway scale, lane numbers, speed and congestion, and tourism factors, such as density or number of attractions of different levels [49].

Through the method of extremum [50], the influence of the value range of figures could be eliminated.

$$
X_{p i}=\frac{x_{p i}-x_{\text {imin }}}{x_{\text {imax }}-x_{\text {imin }}}
$$


By giving weights to different figures, the importance degree could be gained as:

$$
I_{p}=\sum_{i=1}^{n} w_{i} \frac{X_{p i}}{X_{i}}
$$

where $X_{p i}$ and $x_{p i}$ are the standardized and original values of the figures $i$ for node $p$. When the figures are positive ones, the figure value equals to the original value. When the figures are negative, the figure value should be transferred to its reciprocal. $w_{i}$ is the weights for figure $i$, and is given by the decision makers or experts, largely depending on local conditions. $X_{i}$ is the arithmetic mean of the standardized values of the figures $i$ for nodes in the planning area.

Then it is verified that the importance degree of the node is proportional to the network scale of this node [51]:

$$
I_{p}\left(L_{a}, X_{s}, X_{t}, X_{e}, \ldots \ldots\right) \propto L_{a}
$$

Particularly, on a certain tourism node $p$ we have the following relationship between them:

$$
\frac{I_{j}^{p}-I_{k}^{p}}{L_{j}^{p}-L_{k}^{p}}=c_{p}
$$

Further, we also have a character of the constant $c_{p}$ :

$$
c_{p}\left(X_{s}, X_{t}, X_{e}, \ldots .\right) \propto X_{s}, X_{t}, X_{e}, \ldots \ldots
$$

Then, the importance degree of the corresponding node, to the point of which the cumulative percentage of highway scale is $k$ on the tourism matching curve, could be calculated as follows:

$$
I_{k}=\sum_{p=0}^{\lceil K-1\rceil} c_{p} \times\left(L_{\text {max }}^{p}-L_{\text {min }}^{p}\right)+c_{p}^{\lceil K\rceil} \times\left(L^{K}-L_{\text {min }}^{K}\right)
$$

Further, concerning any two points $j$ and $k(j \geq k)$ on the tourism traffic matching curve, we have the following relational expression:

$$
\begin{aligned}
\frac{I_{j}}{I_{k}} & =\frac{\sum_{p=0}^{[J-1]} c_{p} \times\left(L_{\max }^{p}-L_{\min }^{p}\right)+c_{p}^{[J]} \times\left(L^{J}-L_{\min }^{J}\right)}{\sum_{p=0}^{[K-1]} c_{p} \times\left(L_{\min }^{p}-L_{\min }^{p}\right)+c_{p}^{[K]} \times\left(L^{K}-L_{\min }^{K}\right)} \\
& =1+\frac{\sum_{p=[K]}^{[J-1]} c_{p} \times\left(L_{\max }^{p}-L_{\min }^{p}\right)}{I_{k}}+\frac{c_{p}^{[]} \times\left(L^{J}-L_{p}^{\min }\right)}{I_{k}}+\frac{c_{p}^{[K-1]} \times\left(L^{K}-L_{\min }^{K}\right)}{I_{k}}
\end{aligned}
$$

When the distance between point $j$ and point $k$ is large enough, the following three equations would be satisfied as:

$$
\begin{gathered}
\left(L^{J}-L_{\text {min }}^{J}\right) \rightarrow 0 \\
\left(L^{K}-L_{\text {min }}^{K}\right) \rightarrow 0 \\
{\left[c_{p}^{[J]} \times\left(L^{J}-L_{\text {min }}^{J}\right)+c_{p}^{\lceil K-1\rceil} \times\left(L^{K}-L_{\text {min }}^{K}\right)\right] / I_{k} \rightarrow 0}
\end{gathered}
$$

Then for the overall allocation of the curve, we have following relationships between the importance degree of any two points:

$$
\frac{I_{j}}{I_{k}} \approx 1+\sum_{p=\lceil K\rceil}^{\lceil J-1\rceil} c_{p} \times\left(L_{\max }^{p}-L_{\min }^{p}\right) / I_{k}
$$


In addition, when both points are certain, the value of $\left(L_{p}^{j}-L_{p}^{[k]}\right)$ and $I_{k}$ are constant. Meanwhile, the bigger the numeric of $\frac{I_{j}}{I_{k}}$ is, the bigger corresponding $c_{p}$ of the node $p$ between $j$ and $k$ is, accompanied by a bigger angle of $\angle \theta$. See Figure 3 .

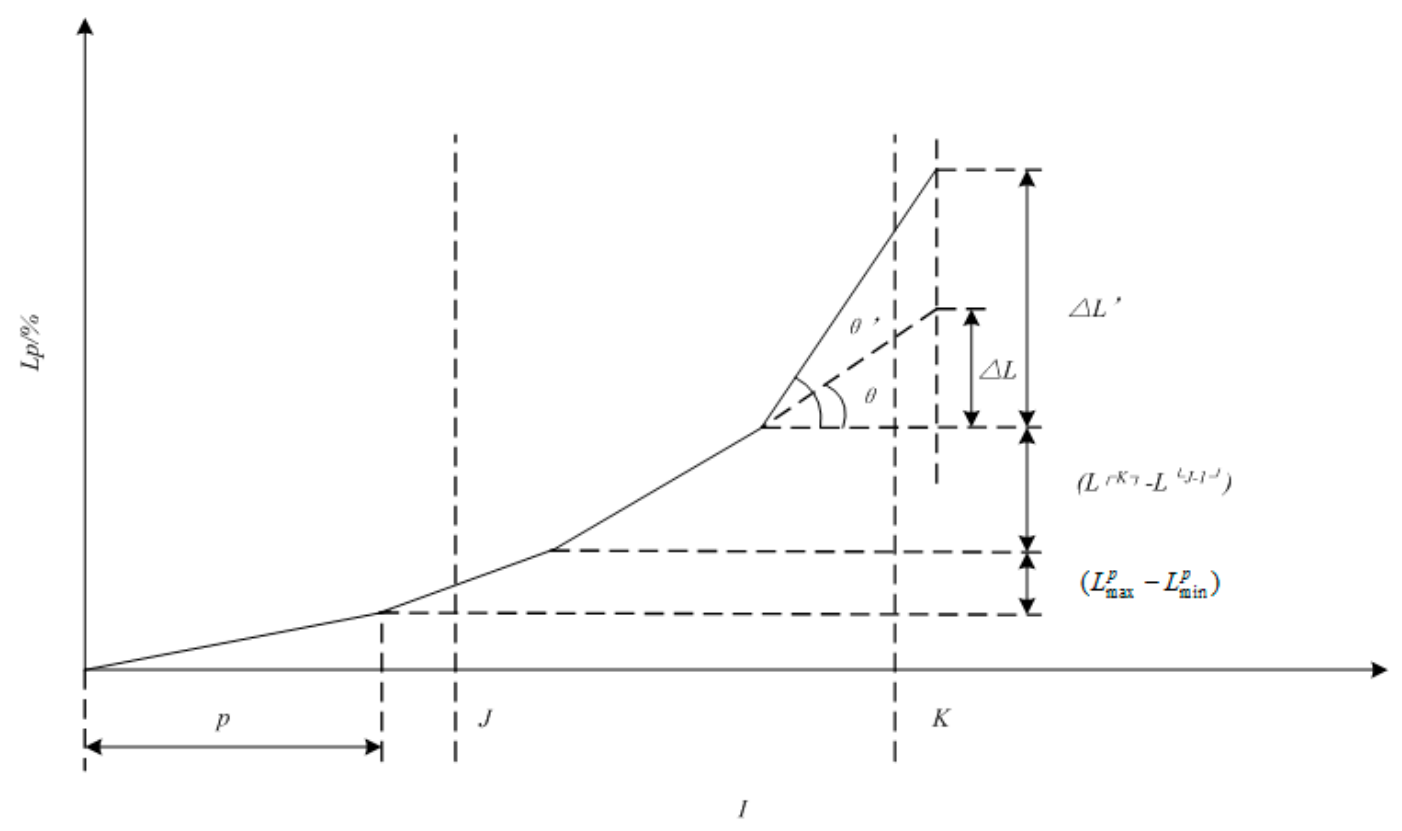

Figure 3. The example of the tourism traffic matching curve.

On the basis of the definition of the tourism traffic matching curve, we have the equation of the highway scale of the node:

$$
\begin{aligned}
L_{p} & =\int_{p=0}^{p} L_{a} d p / \int_{p=0}^{p \max } L_{a} d p \times 100 \% \\
& =\left(\int_{p=0}^{p-1} L_{a} d p+L_{a}^{p}\right) / \int_{p=0}^{p \max } L_{a} d p
\end{aligned}
$$

Considering that in the same tourism traffic network, $\int_{p=0}^{p m a x} L_{a} d p$ is constant, we gain access to this equation:

$$
L_{p} \propto L_{a}
$$

As is provided in Equation (15), the direct proportion is proved as follows:

$$
\left(L^{J}-L^{K}\right) \propto I_{p}^{2}
$$

Consequently, we come to a conclusion that:

$$
\frac{d L_{p}}{d I_{p}}=2 I_{p}
$$

where, to sum up, two characteristics of the tourism traffic matching curve are found as:

1. In relation to any two points, the ratio of their importance degree is associated with the socioeconomic and the tourism resource of all the nodes between them.

2. In general, the slope of a reasonable tourism traffic matching curve shows an increasing rise as a whole. This is because the characteristics of the socioeconomic, tourism resource, and geographic environments of the node $p$ would increase with the growth of the importance degree of the tourism nodes. 


\subsection{Evaluation Indexes and Criterion}

\subsubsection{Tourism Traffic Network Uniformity Coefficient}

The Tourism Traffic Network Uniformity Coefficient (TLCU) reflects the allocation of the highway scale on different importance degrees of tourism nodes in the given network. We utilize the following formula:

$$
T L C U=\frac{I_{60}}{I_{10}}
$$

where $I_{10}$ and $I_{60}$ are the corresponding importance degree of the nodes, of which the cumulative percentage of highway scale in the given network reaches 10 and 60 respectively. In general, $I_{10}, I_{30}$, and $I_{60}$ are selected as the control points, making it possible to show the overall trend of the complete curve.

Further, the bigger TLCU is, the wider the range of highway scale could reach. Then the equilibrium is ranked better in the corresponding tourism traffic network. We make $T L C U_{u b}$ and $T L C U_{d b}$ the upper boundary (UB) and lower boundary (DB) of reasonable coefficient of TLCU, then the condition that $T L C U<T L C U_{d b}$ means a poor match, and the network is heterogeneous and that $T L C U>T L C U_{u b}$ means a desired match. Note that when TLCU appears to be too large, it implies a jump phenomenon that could be found in a specific range of the highway scale; then the match turns out to be disproportional, and needs to be judged with the aid of another index, i.e. the tourism traffic network curvature coefficient.

\subsubsection{Tourism Traffic Network Curvature Coefficient}

The Tourism Traffic Network Curvature Coefficient (TLCC) reflects the smoothness and the entire shape of the tourism traffic matching curve, of which we utilize the following formula:

$$
T L C C=\frac{I_{30}}{I_{60}} / \frac{I_{10}}{I_{30}}
$$

where $I_{30}$ is the corresponding importance degree of the node, of which the cumulative percentage of the highway scale in the given network reaches 30 .

We make $T L C C_{u b}$ and $T L C C_{d b}$ the upper and lower boundary of the reasonable coefficient of $T L C C$, then the condition that TLCC $\in\left[T L C C_{d b}, T L C C_{u b}\right]$ means a desired match. While the condition that TLCC $>T L C C_{d b}$ or TLCC $<T L C C_{u b}$ means a jump phenomenon could be found in between $I_{30}$ and $I_{10}$, or $I_{30}$ and $I_{60}$ of the highway scale, then the change in the highway scale tends to be too large and the equilibrium would be ranked as disappointing.

\section{Results and Discussion}

\subsection{Data Description}

To provide proof of the feasibility and effectiveness of the double-layered coupling system in this paper, a numerical experiment is performed on a real-world subarea network in Guangdong Province, China, to optimize and evaluate the equilibrium of the tourism traffic network. Guangdong Province is located in the southern part of China, which mainly consists of flatlands and hilly land, covering an area of 179,800 square kilometres. Its central geographical coordinates are latitude $22^{\circ} 72^{\prime} \mathrm{N}$ and longitude $113^{\circ} 29^{\prime} \mathrm{E}$, and notably, the region has the longest mainland coastline of 3368.10 kilometres among the provinces of China, as shown in Figure 4a. With subtropical and tropical climates, the annual weather characteristics of this province located in the East Asian monsoon region are regular. The monthly average temperature peaks at $28.5{ }^{\circ} \mathrm{C}$ in July and bottoms out at $13.3^{\circ} \mathrm{C}$ in January. Although the yearly rainfall in Guangdong is abundant, $80 \%$ of the flood season occurs from April to September. The yearly rainfall is usually variable and difficult to identify due to the uncertain paths, intensities, and occurrences of typhoons. Considering that the temperature difference in a year is 
small and the distribution of the monthly rainfall tends to be concentrated in specific seasons, the weather and seasonal influences on tourism traffic sustainability are steady and limited. Moreover, the most popular tourist season in China normally coincides with the national holiday. Therefore, our sustainability goal of tourism traffic network optimization is to satisfy both the tourism and daily peak traffic flow demands in a year as much as possible, which would then be acceptable for any other occasion in the future. By changing the roads design to cater for the needs of the prospective peak flow, we could not only reduce economic costs to society, but also spare room for other kinds of infrastructure in the environment, without having to pay extra fees and space resources for traffic management and rebuilt facilities under the requirements of seasonal traffic flow.

Tourism in Guangdong Province has developed at an astounding rate in recent years. Regarding the reasons for the province's prosperity, the gross domestic product (GDP) in successive years should not be neglected, which has allowed Guangdong Province to reach the global upper-middle income level. It is also noteworthy that the Pearl River Delta region accounts for $80.2 \%$ of the GDP in Guangdong. A high-income level allows people to spend more money on recreational activities such as travel. It is reported that the tourism income of Guangdong Province nearly tripled from 2011 to 2015, to 1037 billion yuan, which resulted in an increase in the GDP from $5.2 \%$ to $6.4 \%$. Moreover, the investments in tourism projects have reached 103 billion yuan, which undoubtedly provided ample support for the development of the local tourism industry. In addition, vehicle ownership in Guangdong Province has also experienced a substantial increase of $13.0 \%$, thereby making Guangdong Province the province with the highest vehicle-ownership level (approximately $9.0 \%$ ) in China. This phenomenon is also the reason that an increasing number of tourists feel compelled to choose the highway network as their transportation mode. In comparison to trains and planes, it seems that highway transportation fits the door-to-door travel model better, especially for the mountainous area in Guangdong, where a considerable number of well-known tourist attractions are located. In addition, this mode affords higher passenger comfort and convenience levels, since ticket-booking in advance is unnecessary. In the view of the increasing number of tourists and accompanying road users, we should put even more emphasis on the potential growth of both the demand for traffic resource and the risk of environmental pollution. It is noticeable that these environmental and human factors, such as social expenditure, people's health, and depletion of non-renewable resources, are intermediate indicators and highly correlated with final outcomes [51]. Thus, we could quantify these costs with indicators like construction fee and pollutants emissions, which were mentioned in socioeconomic benefits, levelling the benefits of tourism and traffic resources, and green benefits as final indicators.

Though the demand for tourism and highway transportation is expected to continue to flourish, the tourism traffic resources in Guangdong Province are still limited and require a more efficient use. Today, Guangdong's population consists of 1.13 billion people with relatively little arable land. The unutilized land occupies only $7.23 \%$ of the total area of the province. A better development in the long term calls for the balance of the limited resource of traffic and tourism, and only in this way can we utilize the built roads better and reduce traffic congestion, which would help to improve human health, and limit both the vehicle emission and the resource consumption. To specify the distribution of tourism traffic resources, Figure 5 depicts three typical figures, i.e., the average travel speed, the number of level 3 and 4 mainlines, and the number of attached $4 \mathrm{~A}$ tourist spots, which together reflect the imbalance between the traffic service levels and the abundance of tourist attractions in the different cities. Note that all the figures are standardized for the sake of direct comparison. For example, node $\mathrm{X} 3$ has the largest share of $4 \mathrm{~A}$ tourist spots and a lower than average number of level 3 and 4 mainlines, which determines the accessibility of the tourist spots. Because the mainlines bear more door-to-door traffic, the current set would be unreasonable, and more level 3 and 4 mainlines are suggested. Likewise, node $\mathrm{X} 9$ possesses more tourism traffic resources than needed. 


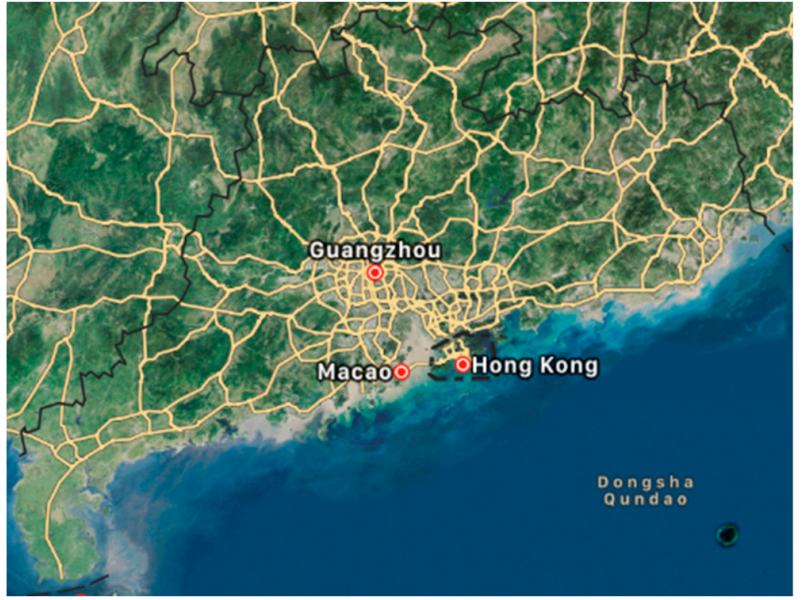

(a)

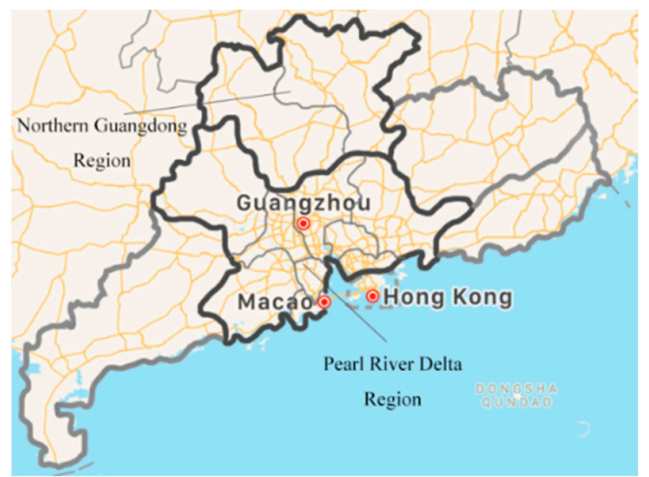

(c)

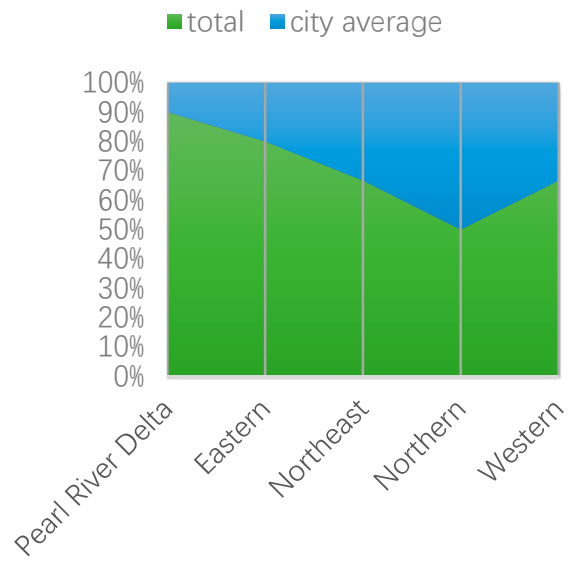

(b)

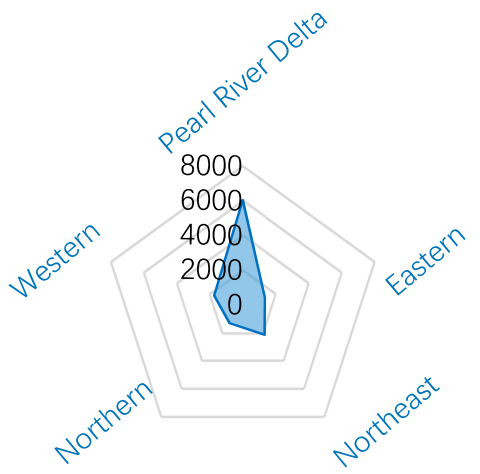

(d)

Figure 4. Highway distribution in different tourist regions of Guangdong Province: (a) Location of planning area; (b) typical region of the area; (c) comparison of scale percentage; (d) highway scale distribution of five regions (unit: $\mathrm{km}$ ).

For more information about the differences in tourism traffic resources among the nodes, we show the resource distributions of five districts, which were divided by geography and tourist spots based on collected fundamental data and survey results from local government institutes, including the Transportation Department and Tourist Administration [52], as shown in Figure 4c. Among the tourism resources, there are a total of 281 scenic spots of a level higher than $3 \mathrm{~A}$ (ranked by the government in accordance with its popularity, quality, service level, number of tourists, etc.). Among these tourist spots, the Pearl River Delta region occupies $52 \%$ of the total number of tourist spots. In regard to the traffic resources, there are 282 ordinary tourism highway mainlines in the given area, and the highway length has already reached 13,990.33 km [53]. Notably, the highway length in the Pearl River Delta region has surpassed 6000 kilometres, while the highway length in the rest of the region has stayed at only approximately 2000 kilometres, nearly 1/3 of that of the Pearl River Delta region. Furthermore, the Pearl River Delta region accounts for nearly $90 \%$ of the tourism traffic highway scale of tourism traffic, with the lowest level of city average scale. In contrast, the highest city average scale occurs in the north region, where the corresponding highway length was the lowest among all the districts, as shown in Figure $4 b$.

Overall, a tourism and traffic resource imbalance could still be observed with regard to the tourism traffic network of Guangdong Province, and the corresponding optimization of resource matching is urgently needed to guarantee future sustainability. In this way, we should place more emphasis on the increasing tourism traffic demands exerted on highway networks and the matching problems between these two aspects of resource. 

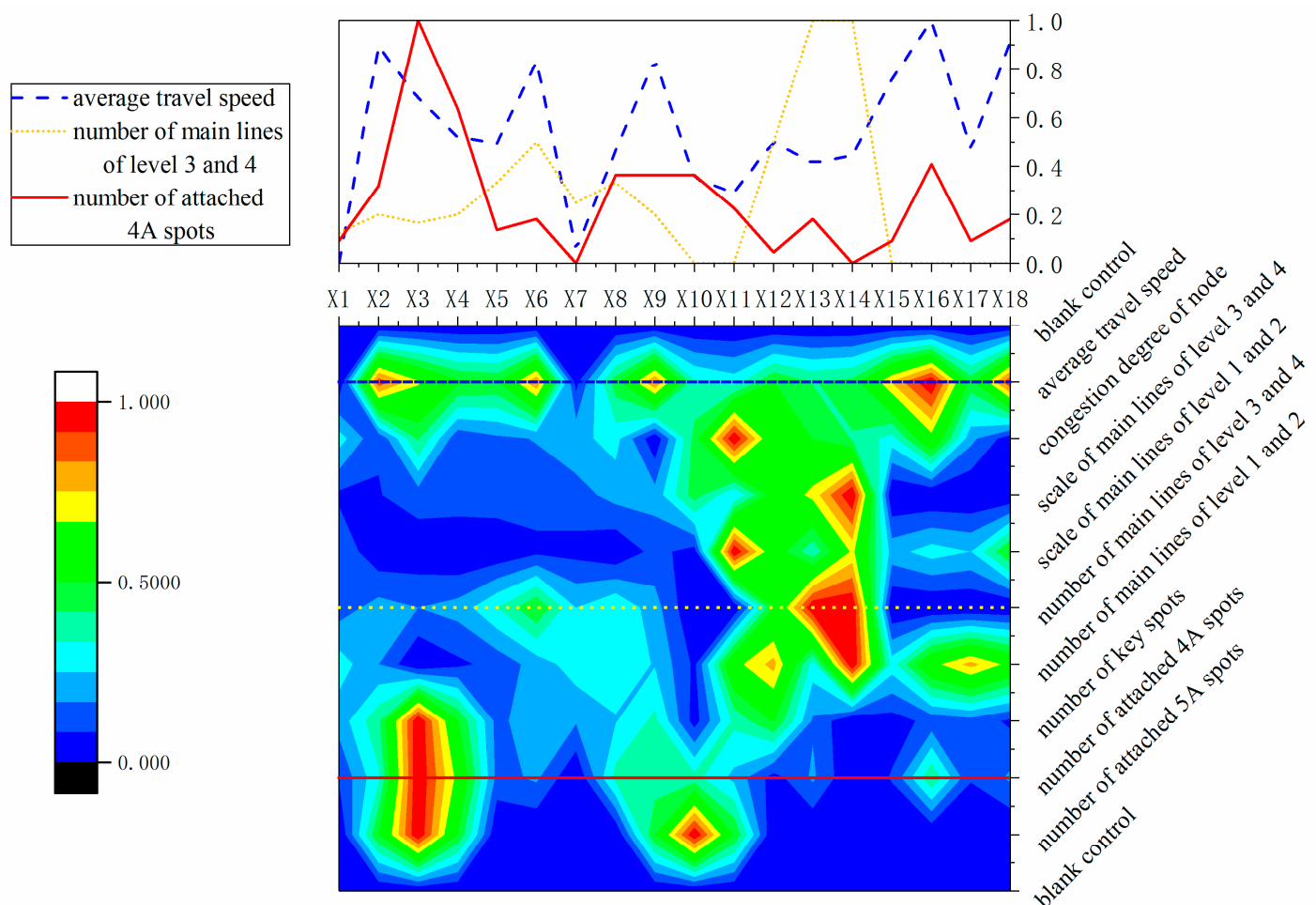

Figure 5. Comparison of representative standardized indicators of tourism and traffic.

\subsection{Evaluation and Advice on the Tourism Network}

Following the basic flow path of the double-layered coupling system in Section 2, we provide a complete scheme for the optimization and evaluation of the network in question. First, 18 cities in the area were selected as control points. Then, the importance degree of the nodes could be calculated based on typical indexes, as shown in Figure 5. The method follows the achievements of Yang et al. [35], and the results are represented in Table 1. Second, the raw data are subsequently processed and transformed into a suitable matrix, which is used to draw the current tourism traffic matching curve. Next, the coefficients of the model in the upper layer are determined according to the government institute data, including compiled traffic surveys [52] and annual statistic reports of China [53]. Basically, the anticipated tourism traffic network length that we obtained through grey forecasting was $28,962.84 \mathrm{~km}$, which is a character prediction method through time-series of relevant features including population and land use. The weights of the socioeconomic benefits, tourism and traffic levelling, and green benefits are $0.40,0.35$, and 0.25 , respectively, and the proposed saturation of the network is 0.60 . On the basis of the levels of the three benefits, the standardized coefficient is set as $1.0 \times 10^{3}, 2.5 \times 10^{3}$, and $1.0 \times 10^{3}$, respectively. Then, the genetic algorithm is introduced to solve the model, and the rate of the convergence peak is calculated according to the following constraints: the population is 100 , the crossover probability is 0.80 , and the deviation value of the fitness function is 1e-100. The results are shown in Figure 6, and the optimal solution of the objective function is 2.09585. Twenty groups of Pareto solutions are obtained after multiple iterations, which function as a reference for the value ranges of TLCU and TLCC. Consequently, the upper and lower boundaries of TLCU are calculated as 7.34 and 4.13, respectively, and those of TLCC are 3.40 and 2.61, respectively.

Based on Equations (26) and (27), the matching results of the existing tourism traffic network of Guangdong Province are not the best, but still acceptable, as indicated by Table 2. The TLCU results indicate that the jump phenomenon does not occur in the current network, whereas the TLCC value of 3.33 , which is relatively close to the lower boundary of 3.40, suggests that a potential jump phenomenon will likely occur between $I_{30}$ and $I_{60}$ on the curve, and the corresponding city (node) is X10 to X15. Moreover, as is shown on the matching curve in Figure 7, it is clear that at a node importance degree 
from 0.90 to 1.40 , i.e., $X 10$ to $X 15$, the nodes appear to exhibit an overly high intensity in the distribution of the highway length. This finding indicates that the calculation has been shown to correspond to the actual distribution, which helps to support not only the conclusion, but also the feasibility and effectiveness of the system. The evaluation also suggests that we should place more emphasis on tourism traffic development in cities $\mathrm{X} 10$ to $\mathrm{X} 15$ in the future.

Furthermore, as explained above, the importance degree increases along the abscissa. In other words, the nodes on the right side are of greater importance than those on the left side. Therefore, we should prioritize the reconstruction of the right nodes over the left nodes, that is, X15 to X10. At X15, the slope of the corresponding range appears to be smaller than the advised curve, which suggests a shortage of tourism traffic highways. The reason is that the number of highways at both levels is limited, which results in limited route selection options for tourists. The slopes of X10, X12, and X13 tend to be higher than the suggested values owing to the limited number of local tourist spots, which indicates that these cities have enough traffic resources and the potential to bear more tourism traffic. This result also means that more tourism projects are welcome at these nodes, which could result in the tourism traffic network being utilized more effectively. There are few suggestions for X11 and X14, and decision makers could adjust their planning based on their needs.

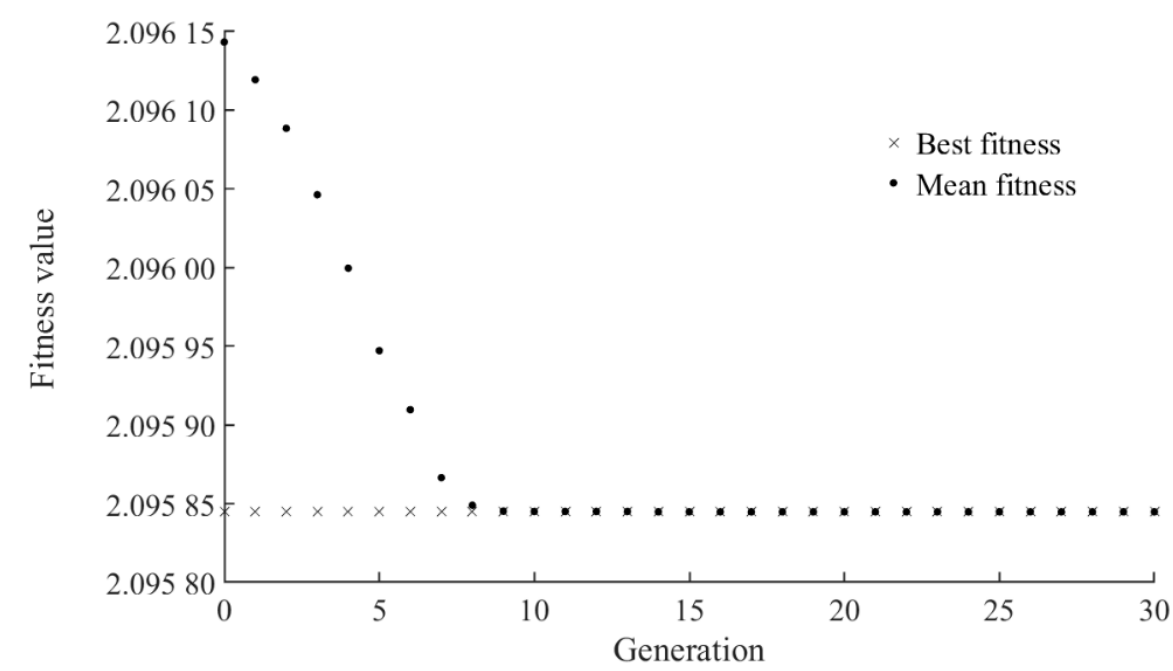

Figure 6. Iteration of the model in the upper layer (the 15th group of Pareto Solution).

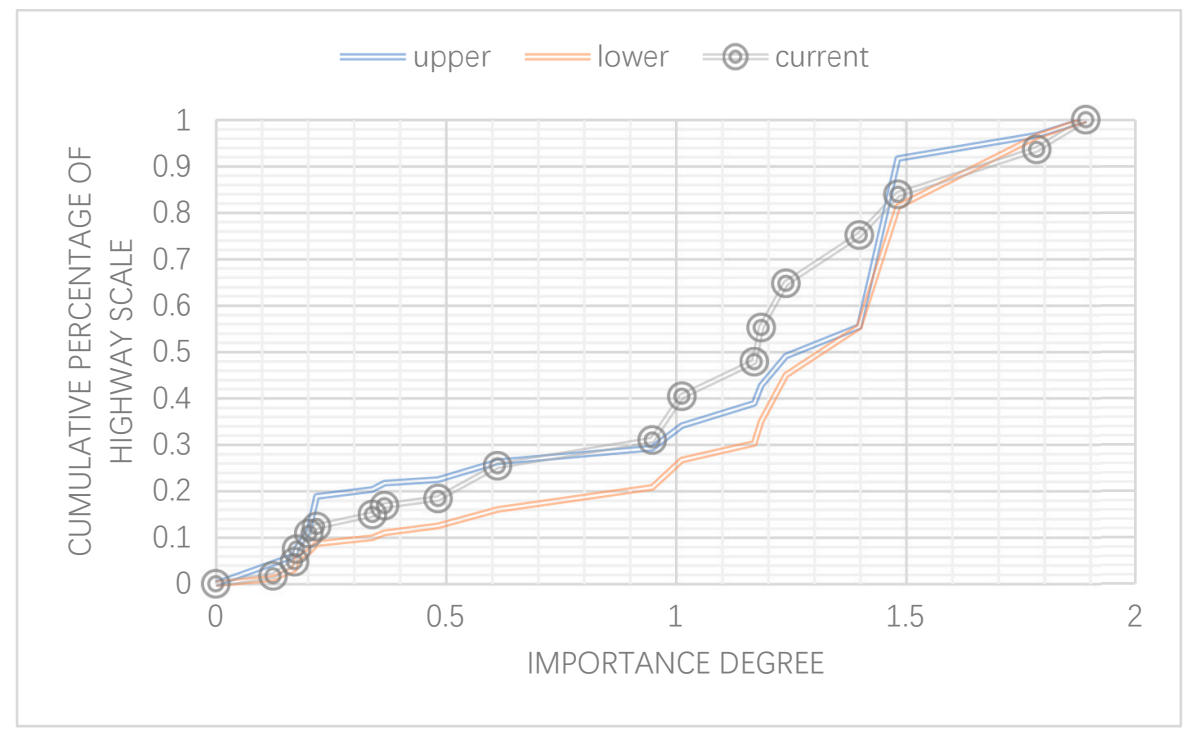

Figure 7. Comparison of the Tourism Traffic Matching Curve of Guangdong Province. 
Table 1. Summary of the current tourism traffic network of Guangdong Province.

\begin{tabular}{cccc}
\hline Node Code & Current Scale/km & Importance Degree & $\begin{array}{c}\text { Cumulative Percentage of } \\
\text { Highway Scale }\end{array}$ \\
\hline X1 & 219.32 & 0.12 & 1.75 \\
X2 & 380.56 & 0.17 & 4.78 \\
X3 & 344.48 & 0.18 & 7.52 \\
X4 & 415.80 & 0.20 & 10.83 \\
X5 & 191.90 & 0.22 & 12.36 \\
X6 & 324.27 & 0.34 & 14.94 \\
X7 & 236.48 & 0.37 & 16.82 \\
X8 & 197.25 & 0.48 & 18.39 \\
X9 & 885.30 & 0.61 & 25.44 \\
X10 & 696.88 & 0.95 & 30.99 \\
X11 & 1184.74 & 1.01 & 40.42 \\
X12 & 937.49 & 1.17 & 47.89 \\
X13 & 923.37 & 1.18 & 55.24 \\
X14 & 1194.90 & 1.24 & 64.75 \\
X15 & 1307.81 & 1.40 & 75.16 \\
X16 & 1099.65 & 1.48 & 83.92 \\
X17 & 1218.53 & 1.78 & 93.62 \\
X18 & 801.24 & 1.89 & 100.00 \\
\hline
\end{tabular}

Table 2. Results of the current tourism traffic network of Guangdong Province.

\begin{tabular}{cccccc}
\hline Standards & Evaluation & UB & Evaluation & DB & Evaluation \\
\hline$T L C U$ & Poor match & 7.34 & Acceptable & 4.13 & Good match \\
current network & & & 6.20 & \\
\hline$T L C C$ & Step in low level & 3.40 & Good equilibrium & 2.61 & Step in high level \\
current network & & & 3.33 & \\
\hline
\end{tabular}

\section{Conclusions}

The accompanying increased traffic due to the rapid development of tourism at present calls for the better sustainability and equilibrium of tourism and traffic resources in the future. This paper proposed a double-layered coupling system focusing on tourism traffic, which combined optimization of the network structure and adjustment of future resource levels in a systematic way.

In the upper layer of the system, we examined three main tourism traffic factors, i.e., socioeconomic benefits, levelling benefits of tourism and traffic resources, and green benefits, which have been identified as important aspects of the multi-objective model. The socioeconomic benefits mainly consist of the optimization cost of the tourism traffic network and the time cost saved for road users. The levelling benefits of tourism and traffic resources comprise both the investment and income of tourism projects. Last but not least, emission of carbon dioxide is set as a fundamental index of green benefits. This comprehensive benefit-oriented model not only paves the way to utilize the importance degree of nodes to quantify the long-neglected radiation effect of the tourism economy, but also has a more concise format, and the involved factors are more relevant compared with other models. In addition, a genetic algorithm approach with adapted parameters has been developed to solve the established model. Through the adjustment of relevant parameters, Pareto solutions were obtained at a high-iteration speed.

In the lower layer, we introduced the idea of the tourism traffic matching curve, which provided a direct and efficient evaluation method for the equilibrium of the tourism traffic network. On the curve, the abscissa and the vertical axis stand for the importance degree of the tourism node and the cumulative percentage of the network scale respectively. It is notable that the slope change of the curve could evaluate the equilibrium of allocations of the network, and that the boundaries of two indicators, i.e., TLCU and TLCC, are calculated in terms of the results of the upper layer and are used 
as evaluation criteria. Thus, the corresponding indicators of the current network could be determined and compared with standards, which results in an effective evaluation of the tourism traffic network.

The practical case study in this paper provided proof of the feasibility and effectiveness of the proposed system, based on graphs and concise results. Genetic algorithm parameters are adjusted to make the iteration process more efficient, including a population of 100, a crossover probability of 0.80 and a deviation value of the fitness function of 1e-100. In addition, the upper and lower boundaries of $T L C U$ are 7.34 and 4.13, respectively, in this case, while those of TLCC are calculated as 3.40 and 2.61, respectively. Relative to the current indicators, a certain range was successfully identified wherein jump phenomena could possibly occur. More importantly, the calculation results agreed with the tourism matching curve. Certain nodes with imbalanced resources of tourism and traffic are identified, and detailed suggestions on sustainability and resource equilibrium are provided for these nodes.

Compared to traditional network optimization, the proposed method has the following advantages:

1. Result visualization via the tourism matching curve makes it possible to identify nodes that have imbalanced tourism and traffic resources, and provides direct information about the node importance and corresponding scale, which can help decision makers determine whether adjustment of the node is urgently required and how large the project can be. The traditional model is very likely to lack any comparison with the current network, and can hardly generate a timetable for the necessity and sequence of network reconstruction measures.

2. The method tends to be very flexible because the parameters in the proposed model can be modified and adapted to different regions on the basis of specific definitions. Through exact classification of the different benefits, decision makers could supplement or eliminate factors and allow these factors to be adapted to different regions. In contrast, the traditional approach lacks adjustment considerations due to a combination of different factors, so that the range of application is limited.

3. The tourism traffic factors that were analyzed in this paper have been systematically determined. Guidance for decision makers to evaluate the network was given in a general way. Traditional equilibrium evaluations tend to not focus on tourism traffic, and neglect certain important aspects, such as radiation effects and green benefits.

4. The proposed optimization and evaluation system can help to guarantee a high efficiency, safety, and availability of tourism road networks, with which policy makers can evaluate the sustainability of their policies in planning from different aspects, i.e. socioeconomic benefits, levelling benefits of tourism and traffic resources, and green benefits.

In summary, the proposed system opens the door to sustainability and evaluation research on tourism and traffic resource levelling. Future research will focus on modification of the proposed $T L C U$ and TLCC in this paper. The main extensions could be adapted to regional limitations and road type influences under multimodal transport and mixed-traffic conditions.

Author Contributions: The author Y.Z. analyzed the evaluation results and drafted the original manuscript; H.W. supervised the manuscript; Z.T. polished the writing to make the paper more perfect.

Funding: This research was funded by NATIONAL NATURAL SCIENCE FOUNDATION OF CHINA, grant number 51578247.

Acknowledgments: We would like to thank our partners Xu Xue-jun from the Transport Department of Guangdong Province and Liu Qing-kai from the Beijing University of Technology for their contributions to data collection.

Conflicts of Interest: The authors declare no conflict of interest. 


\section{References}

1. Albalate, D.; Fageda, X. High speed rail and tourism: Empirical evidence from Spain. Transp. Res. Part A Policy Pract. 2016, 85, 174-185. [CrossRef]

2. Beuthe, M.; Jourquin, B.; Geerts, J.F.; à Ndjang'Ha, C.K. Freight transportation demand elasticities: A geographic multimodal transportation network analysis. Transp. Res. Part E Logist. Transp. Rev. 2001, 37, 253-266. [CrossRef]

3. Testa, R.; Galati, A.; Schifani, G.; Di Trapani, A.M.; Migliore, G. Culinary Tourism Experiences in Agri-Tourism Destinations and Sustainable Consumption-Understanding Italian Tourists' Motivations. Sustainability 2019, 11, 4588. [CrossRef]

4. Babazadeh, R.; Razmi, J.; Rabbani, M.; Pishvaee, M.S. An integrated data envelopment analysis-mathematical programming approach to strategic biodiesel supply chain network design problem. J. Clean. Prod. 2017, 147, 694-707. [CrossRef]

5. Rezaee, A.; Dehghanian, F.; Fahimnia, B.; Beamon, B. Green supply chain network design with stochastic demand and carbon price. Ann. Oper. Res. 2017, 250, 463-485. [CrossRef]

6. Wu, K.H.; Chen, Y.Y.; Ma, J.M.; Bai, S.; Tang, X.R. Traffic and emissions impact of congestion charging in the central Beijing urban area: A simulation analysis. Transp. Res. Part D Transp. Environ. 2017, 51, $203-215$. [CrossRef]

7. Graham, D.J.; Mccoy, E.J.; Stephens, D.A. Quantifying Causal Effects of Road Network Capacity Expansions on Traffic Volume and Density via a Mixed Model Propensity Score Estimator. J. Am. Stat. Assoc. 2014, 109, 1440-1449. [CrossRef]

8. David, D. The Japanese experience with highway development. J. Infrastruct. Dev. 2014, 6, 17-42. [CrossRef]

9. Li, J.S.; Rong, G.; Feng, Y.P. Request selection and exchange approach for carrier collaboration based on auction of a single request. Transp. Res. Part E Logist. Transp. Rev. 2015, 84, 23-39. [CrossRef]

10. Song, H.Q.; Cheung, R.K.; Wang, H.Y. An arc-exchange decomposition method for multistage dynamic networks with random arc capacities. Eur. J. Oper. Res. 2014, 233, 474-487. [CrossRef]

11. Xiao, Y.Y.; Konak, A. The heterogeneous green vehicle routing and scheduling problem with time-varying traffic congestion. Transp. Res. Part E Logist. Transp. Rev. 2016, 88, 146-166. [CrossRef]

12. Deng, Y.; Yang, Y.; Ma, R. Highway network structure characteristics based on complex network theory. China J. Highw. Transp. 2010, 23, 98-104.

13. Zhao, F.X.; Sun, H.J.; Wu, J.J.; Gao, Z.Y. Urban Road Network Evolution to Maximize the Capacity. In Proceedings of the 9th International Conference on Traffic and Transportation Studies (ICTTS 2014), Shaoxing, China, 1-2 August 2014; Available online: http://www.sciencedirect.com/science/article/pii/ S1877042814041214 (accessed on 14 July 2014).

14. Wang, X.X.; Fu, H.; Lu, J.F.; Han, S. Study on road section environmental traffic capacity model and algorithm under double constraints. Transp. Res. Part D Transp. Environ. 2016, 48, 14-19. [CrossRef]

15. Chow, J.Y.J.; Sayarshad, H.R. Symbiotic network design strategies in the presence of coexisting transportation networks. Transp. Res. Part B Methodol. 2014, 62, 13-34. [CrossRef]

16. Shi, L.-Q.; Zhou, W.; Liu, Y.; Yin, X.H. Reasonable Scale Foresting of Regional Highway Network Based on BPNN-MOP. J. Transp. Syst. Inf. Technol. 2010, 10, 150-160.

17. Ma, C.X.; Ma, C.R.; Ye, Q.; He, R.C.; Song, J.Y. An Improved Genetic Algorithm for the Large-Scale Rural Highway Network Layout. Math. Probl. Eng. 2014, 2014, 1-6. [CrossRef]

18. Recker, W.W.; Chen, C.; Mcnally, M.G. Measuring the impact of efficient household travel decisions on potential travel time savings and accessibility gains. Transp. Res. Part A Policy Pract. 2001, 35, 339-369. [CrossRef]

19. Li, G.C.; Li, B.R.; Ju, M.Y.; Zhang, Z.J. Discussion on Integrated Traffic Planning(ITP) of New Tourism Town upon Sustainable Development and Livable Request. In Proceedings of the World Conference on Transport Research-WCTR 2016, Shanghai, China, 10-15 July 2017; pp. 3402-3415.

20. Currie, C.; Falconer, P. Maintaining sustainable island destinations in Scotland: The role of the transport-tourism relationship. J. Destin. Mark. Manag. 2014, 3, 162-172. [CrossRef]

21. Ho, C.Q.; Mulley, C. Group travel and public transport use: The effect of fare discounts. In Proceedings of the Australasian Transport Research Forum 2013 Proceedings, Brisbane, Australia, 2-4 October 2013. 
22. Ding, H.; Chen, X.; Zhang, Y.Y. Concept, type and effect of tourism highway in China. J. Chang. Univ. 2013, 33, 67-70.

23. Mirabueno, J.; Yujuico, E. Paving the way for Philippine tourism via interagency collaboration on road networks. Transp. Policy 2014, 36, 306-315. [CrossRef]

24. Mokhtar, S.; Shimizu, T. An analysis of service needs for self-drive tourist: Proposing for better policies for Malaysia's road network. Soc. Technol. Res. Pap. 2016, 13, 22-31.

25. Huang, Z.; Cao, F.; Jin, C.; Yu, Z.; Huang, R. Carbon emission flow from self-driving tours and its spatial relationship with scenic spots-A traffic-related big data method. J. Clean. Prod. 2017, 142, 946-955. [CrossRef]

26. Więckowski, M.; Michniak, D.; Bednarek-Szczepańska, M.; Chrenka, B.; Ira, V.; Komornicki, T.; Rosik, P.; Stępniak, M.; Székely, V.; Śleszyński, P. Road accessibility to tourist destinations of the Polish-Slovak borderland: 2010-2030 prediction and planning. Geogr. Pol. 2014, 87, 5-26. [CrossRef]

27. Abdelghany, A.F.; Mahmassani, H.S. Temporal-Spatial Microassignment and Sequencing of Travel Demand with Activity-Trip Chains. Transp. Res. Rec. 2003, 1831, 89-97. [CrossRef]

28. Abdelghany, A.F.; Mahmassani, H.S.; Chiu, Y.-C. Spatial Microassignment of Travel Demand with Activity Trip Chains. Transp. Res. Rec. 2001, 1777, 36-46. [CrossRef]

29. Peeta, S.; Ziliaskopoulos, A.K. Foundations of dynamic traffic assignment: The past, the present and the future. Netw. Spat. Econ. 2001, 1, 233-265. [CrossRef]

30. Lu, C.-C.; Mahmassani, H.S.; Zhou, X. A bi-criterion dynamic user equilibrium traffic assignment model and solution algorithm for evaluating dynamic road pricing strategies. Transp. Res. Part C Emerg. Technol. 2008, 16, 371-389. [CrossRef]

31. Lu, C.C.; Mahmassani, H.S.; Zhou, X.S. Equivalent gap function-based reformulation and solution algorithm for the dynamic user equilibrium problem. Transp. Res. Part B Methodol. 2009, 43, 345-364. [CrossRef]

32. Smith, M.J. The existence, uniqueness and stability of traffic equilibria. Transp. Res. Part B Methodol. 1979, 13, 295-304. [CrossRef]

33. Smith, M. A new dynamic traffic model and the existence and calculation of dynamic user equilibria on congested capacity-constrained road networks. Transp. Res. Part B Methodol. 1993, 27, 49-63. [CrossRef]

34. Smith, M.; Wisten, M. A continuous day-to-day traffic assignment model and the existence of a continuous dynamic user equilibrium. Ann. Oper. Res. 1995, 60, 59-79. [CrossRef]

35. Jiang, L.; Mahmassani, H.S. Toll Pricing Computational Tests for Capturing Heterogeneity of User Preferences. Transp. Res. Rec. 2013, 105-115. [CrossRef]

36. Jiang, L.; Mahmassani, H.S.; Zhang, K.L. Congestion Pricing, Heterogeneous Users, and Travel Time Reliability Multicriterion Dynamic User Equilibrium Model and Efficient Implementation for Large-Scale Networks. Transp. Res. Rec. 2011, 58-67. [CrossRef]

37. Halat, H.; Zockaie, A.; Mahmassani, H.S.; Xu, X.; Verbas, O. Dynamic network equilibrium for daily activity-trip chains of heterogeneous travelers: Application to large-scale networks. Transportation 2016, 43, 1041-1059. [CrossRef]

38. Zheng, Q.X.; Kuang, Y.Q.; Huang, N.S. Coordinated Development between Urban Tourism Economy and Transport in the Pearl River Delta, China. Sustainability 2016, 8, 1338. [CrossRef]

39. Tirachini, A.; Hensher, D.A.; Rose, J.M. Multimodal pricing and optimal design of urban public transport: The interplay between traffic congestion and bus crowding. Transp. Res. Part B Methodol. 2014, 61, 33-54. [CrossRef]

40. Zheng, N.; Rerat, G.; Geroliminis, N. Time-dependent area-based pricing for multimodal systems with heterogeneous users in an agent-based environment. Transp. Res. Part C Emerg. Technol. 2016, 62, 133-148. [CrossRef]

41. Khoshnevis Yazdi, S.; Khanalizadeh, B. Tourism demand: A panel data approach. Curr. Issues Tour. 2017, 20, 787-800. [CrossRef]

42. Aaheim, A.; Romstad, B.; Wei, T.; Kristjánsson, J.E.; Muri, H.; Niemeier, U.; Schmidt, H. An economic evaluation of solar radiation management. Sci. Total Environ. 2015, 532, 61-69. [CrossRef]

43. Wang, X.; Li, X.; Zhen, F.; Zhang, J.H. How smart is your tourist attraction?: Measuring tourist preferences of smart tourism attractions via a FCEM-AHP and IPA approach. Tour. Manag. 2016, 54, 309-320. [CrossRef]

44. Al-Mulali, U.; Fereidouni, H.G.; Mohammed, A.H. The effect of tourism arrival on $\mathrm{CO}_{2}$ emissions from transportation sector. Anatolia 2015, 26, 230-243. [CrossRef] 
45. Casals, L.C.; Martinez-Laserna, E.; García, B.A.; Nieto, N. Sustainability analysis of the electric vehicle use in Europe for CO2 emissions reduction. J. Clean. Prod. 2016, 127, 425-437. [CrossRef]

46. Marufuzzaman, M.; Eksioglu, S.D. Designing a Reliable and Dynamic Multimodal Transportation Network for Biofuel Supply Chains. Transp. Sci. 2017, 51, 494-517. [CrossRef]

47. Spiess, H.; Florian, M. Optimal strategies: A new assignment model for transit networks. Transp. Res. Part $B$ Methodol. 1989, 23, 83-102. [CrossRef]

48. Leblanc, L.J.; Morlok, E.K.; Pierskalla, W.P. An efficient approach to solving the road network equilibrium traffic assignment problem. Transp. Res. 1975, 9, 309-318. [CrossRef]

49. Liu, B.; Ye, L.; Jiang, J. Forecasting seismic damage in multistory masonry bulidings with a neuro-fuzzy approach. J. Tsinghua Univ. 2002, 42, 843-846.

50. Zhang, R.Y.; Xi, J.C.; Wang, S.K.; Wang, X.G.; Ge, Q.S. Village network centrality in rural tourism destination: A case from Yesanpo tourism area, China. J. Mt. Sci. 2015, 12, 759-768. [CrossRef]

51. Marzieh, R.; Lu, A.; Abbas, R.; Tuan, N. Transport sustainability index: Melbourne case study. Ecol. Indic. 2014, 43, 288-296.

52. Department of Transportation of Guangdong Province, Development and Reform Commission of Guangdong Province, China. Highway Network Planning of Guangdong Province (The Year of 2020-2030). 2016. Available online: http://td.gd.gov.cn/attachment/0/217/217664/1240019.pdf (accessed on 27 February 2017).

53. National Bureau of Statistics, China. National Economy and Society Developed Statistical Bulletin in the year of 2018. 2017. Available online: http://www.stats.gov.cn/tjsj/zxfb/201902/t20190228_1651265.htm (accessed on 28 February 2019).

(C) 2019 by the authors. Licensee MDPI, Basel, Switzerland. This article is an open access article distributed under the terms and conditions of the Creative Commons Attribution (CC BY) license (http://creativecommons.org/licenses/by/4.0/). 